\title{
Porównanie metod spawania rurociągów preizolowanych
}

\section{Comparison of preinsulated pipelines methods of welding}

\section{Streszczenie}

Przedstawiono wymagania dotyczące spawania rur preizolowanych. Omówiono zalecenia dotyczące wykonywania spoin sczepnych i kolejności układania ściegów. Przedstawiono podstawowe metody spawania rur preizolowanych, zakres stosowania oraz wady i zalety. Porównano koszty spawania z zastosowaniem poszczególnych metod spawania.

Słowa kluczowe: spawanie rur preizolowanych, metody spawania, koszty spawania
Abstract

Requirements put on welding preinsulated tubes are presented in the article. Recommendations related to make positional welds, and an order to make beads are provided. The basic methods of welding preinsulated tubes, a scope of their use, as well as advantages and disadvantages are given. The costs of welding with the use of particular methods of welding are compared.

Keywords: welding preinsulated tubes, methods of welding, costs of welding

\section{Wstęp}

Proces spawania złączy doczołowych przy montażu rur preizolowanych jest jednym z najważniejszych etapów wpływających na trwałość i bezawaryjność sieci ciepłowniczych zgodnie z wytycznymi PE-EN 489 - Sieci ciepłownicze. Trudność wynikająca z miejsca wykonywania spoin, którym w 90\% jest wykop powoduje, że nie wszystkie metody spawania mogą być stosowane. Najczęściej stosuje się takie metody jak; spawanie łukowe elektrodą otuloną, spawanie acetylenowo-tlenowe oraz spawanie metodą TIG [1].

\section{Materiał podstawowy - rury preizolowane}

Materiałem stosowanym na rury przelotowe w rurach preizolowanych jest stal z grupy 1.1 P235TR1 lub TR2 zgodnie z EN 10217-1 lub P235GH zgodnie z EN 10217-2 lub EN 10217-5. Skład chemicznych stali: $C_{\max }: 0.16, P_{\max }: 0.025, S_{\max }$ : $0.020, \mathrm{Mn}_{\max }: 1.2, \mathrm{Si}_{\max }: 0.35$. Stal ta powinna się charakteryzować granicą plastyczności Re $\leq 235 \mathrm{Mpa}$, wytrzymałością na rozciąganie $350<\mathrm{Rm}<480 \mathrm{MPa}$ oraz wydłużeniem względnym A5 równym min. 23\%. W zależności od średnicy (DN20$600)$, rury występują ze szwem wzdłużnym lub spiralnym, grubość ścianki od 2.3 do $8 \mathrm{~mm}$ przy rurze o śr. nom. DN600.

\section{Materiały dodatkowe do spawania}

Ze względu na rodzaj stosowanej metody spawania można wyróżnić takiej materiały dodatkowe jak [2]:

- elektrody otulone (111),

- drut do spawania gazowego (311),
- drut i elektrody do spawania metodą TIG (141).

- gazy osłonowe.

\section{Spawanie łukowe elektrodą otuloną:}

Zalecane przy tej metodzie ze względu na właściwości oraz skład chemiczny są:

- NORMAL EP (E 38 A RC 12) - odpowiednik elektrody ER - 1.46, średnio otulona elektroda rutylowo - celulozowa. Elektrody te należy stosować do wykonywania spoin sczepnych (pamiętając o przetopieniu miejsc sczepień odpowiednią elektrodą - REKORD 38, EXTRA 46).

- EXTRA 46(E 382 RA 12) - odpowiednik elektrody ER 3.46, grubo otulona elektroda rutylowo - kwaśna. Szczególnie zalecana do wykonywania warstw przetopowych w pozycjach przymusowych. Posiada dobrą odbijalność żużla.

- REKORD 38 (E 382 RB 12), odpowiednik elektrody ER - 2.46. Grubootulona elektroda rutylowo - zasadowa, o bardzo dobrych właściwościach spawalniczych, przydatna szczególnie do spawania w pozycji pułapowej oraz do wykonywania warstw przetopowych. Stosowane średnice elektrod 2,5 $\div 6,0 \mathrm{~mm}$. Przy zastosowaniu tej elektrody warstwę przetopową należy wykonać przy pomocy elektrody $2,5 \mathrm{~mm}$. Pozostałe warstwy, wypełnienie i lico wykonać elektrodami o średnicach 3,25 i 4,0 mm. Do warstw wypełnienia i lica stosować również elektrody EXTRA 46. Przy stosowaniu tego rodzaju elektrod zalecane suszenie przez godzinę w temperaturze $100^{\circ} \mathrm{C}$.

\section{Spawanie acetylenowo-tlenowe:}

- Drut SGP1M miedziowany używany przy tej metodzie stosowany jest do spawania stali niskowęglowych (St0S

Dr hab. inż. Jacek Słania, prof. PCz - Politechnika Częstochowska, mgr inż. Kamil Kołacz - „EUROBUD” Częstochowa. Autor korespondencyjny/Corresponding author. jacek_slania@poczta.onet.pl 
do St3SJ, St4SU do St4VB), blach kotłowych(St36K, St41K, St44K) oraz rur (K10, K18, R, R35 i R45).

Spawanie metodą TIG:

- Dobrze sprawdzające się druty lite przy tej metodzie to:

- OK TIGROD 12.64 (W 463 W4Si1), miedziowany pręt spawalniczy o zwiększonej zawartości krzemu i manganu, zapewnia wyższą wytrzymałość spoiny oraz zwiększa odporność na zanieczyszczenia spawanych elementów.

- OK TIGROD 13.09 (W Mo Si), miedziowany, niskostopowy pręt $z$ dodatkiem molibdenu ok. $0.5 \%$ przeznaczony do spawania stali odpornych na pełzanie przy temperaturze pracy do $500{ }^{\circ} \mathrm{C}$ oraz do stali niskostopowych o dużej wytrzymałości na rozciąganie

\section{Gaz ochronny:}

Czysty argon: 11

\section{Przygotowanie do spawania - wymagania}

Większość prac spawalniczych jest wykonywana na budowie w wykopie, co pociąga za sobą odpowiednie przygotowanie miejsca spawania tzn. miejsce to powinno być osłonięte od niekorzystnych warunków atmosferycznych takich jak; wiatr, opady, słońce oraz powinno spełniać zasady bhp i gwarantować pracownikom oraz osobą postronnym (często prace takie wykonywane są w centrach miast, przy chodnikach, zabudowaniach) osłonę przed promieniowaniem łuku spawalniczego. Dlatego też stosuję się namioty z bocznymi ścianami gwarantujące osłonę. Obszar spawania powinien być oczyszczony z farb, olejów, rdzy i resztek pianki PUR, a złącze oczyszczone na ok. $30 \mathrm{~mm}$ do połysku metalicznego zewnątrz i wewnątrz rury za pomocą szlifierek. Wszelkie pracę wykonywane powinny być przy temperaturze nie mniejszej niż $5{ }^{\circ} \mathrm{C}$. Spawanie poniżej tej temperatury jest dopuszczalne jedynie w przypadku awarii ciepłociągu.

Końce rur powyżej grubości ścianki 3,2 mm powinny być ukosowane zgodnie z PN-ISO 6761 oraz przed przystąpieniem do sczepiania rury powinny być wykalibrowane współosiowo za pomocą centrowników w celu zlikwidowaniu ewentualnych owalizacji rur [1].

a)
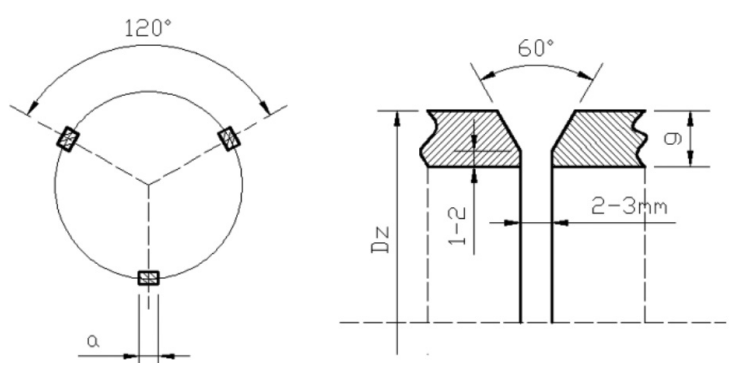

b)
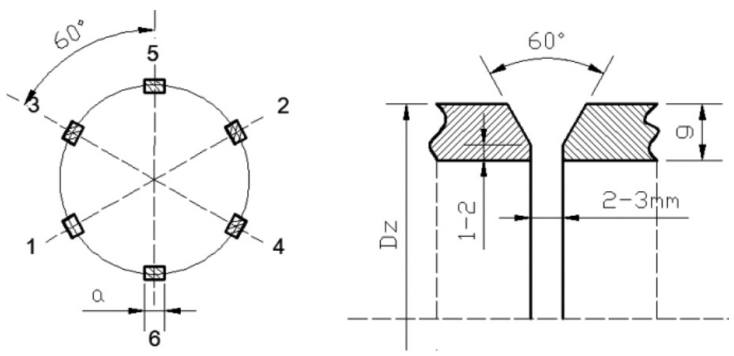

Rys. 1. a) przygotowanie złącza i kolejność wykonania spoin sczepnych dla rur o średnicy poniżej $100 \mathrm{~mm}$ b) przygotowanie złącza i kolejność wykonania spoin sczepnych dla rur o średnicy powyżej $100 \mathrm{~mm}$

Fig. 1. a) preparing a joint, and an order of making positional welds for tubes of a diameter smaller than $100 \mathrm{~mm}$ b) preparing a joint, and an order of making positional welds for tubes of a diameter bigger than
Spoiny sczepne należy wykonywać punktowo symetrycznie na długości co najmniej $25 \%$ obwodu, a ich ilość powinna być wystarczająca do zapewnienia wymaganej wytrzymałości rurociągu. Odstęp po między łączonymi rurami powinna wynosić od 2 do $3 \mathrm{~mm}$ a próg od 1 do $2 \mathrm{~mm}$ w zależności od grubości materiału. Kolejność wykonywania spoin sczepnych pokazano na rysunku $1 \mathrm{a}$ i $1 \mathrm{~b}$.

Po wykonaniu spoin sczepnych, przetop i warstwy kolejne należy wykonywać od dołu i przesuwając się ku górze (pozycja PF) z dwóch stron zaczynając i kończąc w innym miejscu tak jak pokazano na rysunkach $2 \mathrm{a}$ i $2 \mathrm{~b}$.

a)

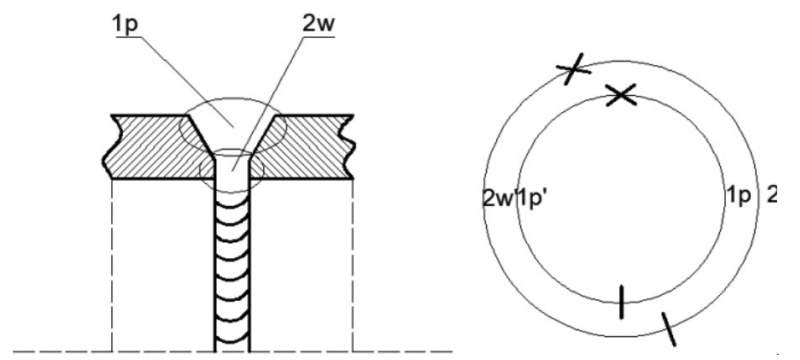

b)

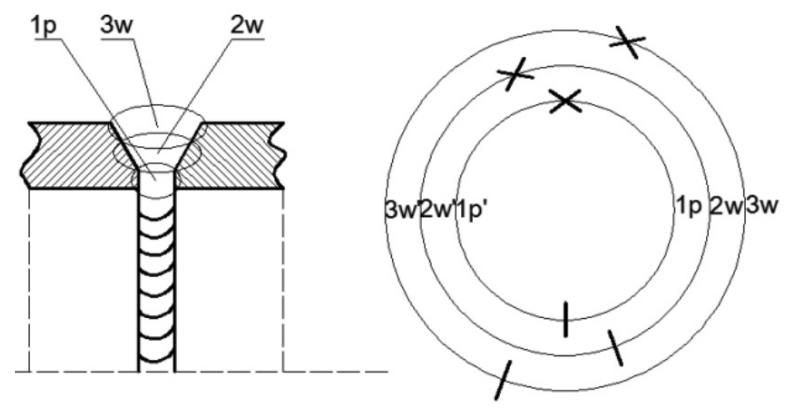

Rys. 2. Kolejność układania ściegów: a) układanie ściegów dla rur o średnicy poniżej $100 \mathrm{~mm}$ b) układanie ściegów dla rur o średnicy powyżej $100 \mathrm{~mm}$

Fig. 2. An order of making beads: a) making beads for tubes of a diameter smaller than $100 \mathrm{~mm}$ b) making beads for tubes of a diameter bigger than $100 \mathrm{~mm}$

- Spawacze, wykonujący spawanie rurociągów powinni posiadać odpowiednie kwalifikacje

- zgodnie z PN-EN 287-1:2011, uprawniające do stosowania danych metod spawania, grup materiałów, zakresu średnic i metod spawania.

- Personel nadzorujący wykonanie prac spawalniczych jest odpowiedzialny za wszystkie prace spawalnicze. Personel ten musi mieć kwalifikacje zgodnie z PN-EN IS014731:2006, odpowiednio do danych wymagań jakościowych określonych w grupie PN-EN ISO 3834:2006.

- Metody spawania muszą być określone i dopuszczone zgodnie z normami PN-EN ISO 15609-1:2007, PN-EN ISO 15609-2:2005

- Materiały dodatkowe powinny posiadać atesty

Elektrody, pręty i druty używane na budowie muszą być przechowywane w odpowiednich warunkach, konieczne jest stosowanie suszarek i termosów do elektrod otulonych.

- Spoiny nie spełniające wymagań muszą być naprawione lub wycięte

- Podczas spawania jeden koniec rury powinien być zaślepiony w celu zapobiegania możliwych przepływów powietrza.

- Szwy wzdłużne lub spiralne powinny być przesunięte względem siebie o $10 \mathrm{~g}$ rury, przy czym minimalna odległość to $50 \mathrm{~mm}$

- Odległość miedzy spoinami powinna być większa niż $5 \mathrm{~g}$ rury [1] 


\section{Porównanie metod spawania}

Wykorzystywane metody spawania przy montażu rur preizolowanych muszą charakteryzować się mobilnością przemieszczania stanowiska, ponieważ na odcinkach prostych rurociągów (poza takimi miejscami jak kolana, trójniki oraz kompensatory) można wykonać tylko dwa złącza a następnie trzeba całe stanowisko przenieś o $12 \mathrm{~m}$ (produkcyjna długość rur preizolowanych). Dlatego też stosuję się głównie trzy metody jak; spawanie łukowe elektrodą otuloną, spawanie metodą TIG ze względu na obecne małe gabaryty tych urządzeń, a w przypadku spawania acetylenowo tlenowego na możliwość stosowania długich węży gazowych.

\section{Spawanie acetylenowo-tlenowe}

Metoda wykorzystywana jedynie do spawania rur preizolowanych o średnicy nominalnej nie przekraczające DN65. Przy większych średnicach strefa przegrzania może być miejscem awarii po uruchomieniu sieci, gdy pojawią się wysokie naprężenia związane z pracą rurociągu (zakres temperatur czynnika grzewczego od 80 do $140^{\circ} \mathrm{C}$ ). Oprócz wady jaką jest ograniczenie wynikające z zakresu spawanych średnic, zaletą tej metody w porównaniu do spawania łukowego elektrodą otuloną jest brak żużla, którego nie trzeba po wykonaniu warstwy usuwać prze szczotkowanie/szlifowanie i zaraz po wykonaniu przetopu można układać kolejną warstwę spoin, co powoduje obniżenie kosztów robocizny oraz redukcje kosztów wiązanych z sprzętem, ponieważ spawanie acetylenowo-tlenowe nie wymaga źródła prądu, którym na budowie przeważnie jest agregat prądotwórczy.

Zalecenia przy stosowaniu spawania acetylenowo-tlenowego:

- Pozycje spawania: wszystkie

- Zakres grubości ścianki: 2-5 mm

- Zakres średnic: DN20-DN65

- Metoda spawania: w prawo

- Ilość warstw: 2

- Średnica drutu: 2,4 i $3 \mathrm{~mm}$

- Nr palnika: 2 i 3

$\mathrm{Na}$ rysunku 3 przedstawiono wygląd lica i grani spoiny rury o średnicy $33,7 \mathrm{~mm}$ i grubości ścianki $2,9 \mathrm{~mm}$. Złącze wykonano metodą 311 .
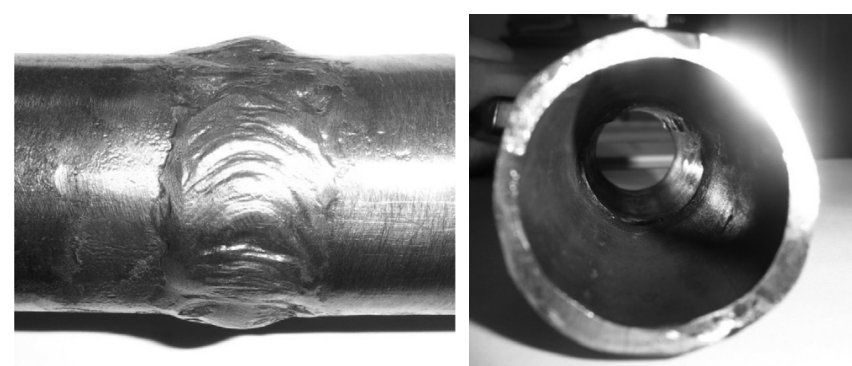

Rys. 3. Lico i grań spoiny rury o średnicy $33,7 \mathrm{~mm}$ i grubości ścianki $2,9 \mathrm{~mm}$

Fig. 3. The face and root of the weld of the $33,7 \mathrm{~mm}$ diameter tube, and $2,9 \mathrm{~mm}$ thick wall

\section{Spawanie elektrodą otuloną}

Najczęściej stosowanym źródłem prądu są spawarki inwertorowe, które cechują się niewielkimi rozmiarami, małą masą oraz znaczną sprawnością energetyczną, co ma wpływ na efekty spawania oraz na mobilność w porównaniu do starszych generacji spawarek wirowych spalinowych. Spawarka taka powinna posiadać zakres prądu spawania w przedziale 30-200A oraz przewody spawalnicze o długości ok. $5 \mathrm{~m}$ w celu zapewnienia wygodniejszej pracy dla spawacza w szczególności przy dużych średnicach rurociągów. Metodą tą można spawać cały zakres średnic rur preizolowanych od DN20 do DN600. Wadami tej metody są odpryski i żużel, które mogą prowadzić do powstania niezgodności oraz konieczność ich usuwania po każdej wykonanej warstwie spoiny więc przy użyciu elektrody otulonej. Wówczas praca jest rozciągnięta $w$ czasie, co powoduje że nie jest to metoda zbyt wydajna, a i umiejętności spawacza odgrywają tutaj niemałą rolę.

\section{Zalecenia przy stosowaniu spawania elektrycznego} elektrodą otuloną:

- Pozycje spawania: wszystkie oprócz PG

- Zakres średnic: DN20-DN600

- Rodzaj prądu: DC-/+

- Przetop: elektroda $2.5 \mathrm{~mm}-70-90 \mathrm{~A}$

- Wypełnienie: elektroda $3.25 \mathrm{~mm}$ - 90-125A

- Lico: elektroda 3.25/4.0 mm, 110-180A

Na rysunku 4 przestawiono wykonane złączę metodą 111 rury o średnicy 139,7 mm i grubości ścianki 3,6 m.
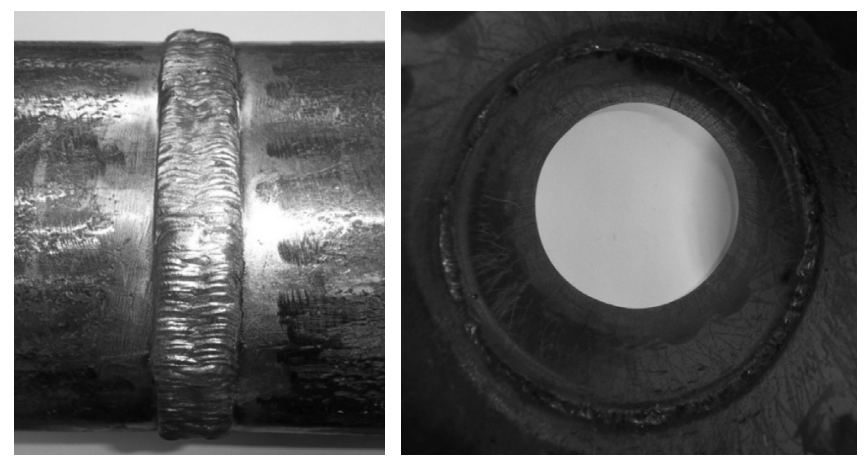

Rys. 4. Złącze rury o średnicy 139,7 mm i grubości ścianki 3,6 mm wykonane metodą 111

Fig. 4. A joint of the $139,7 \mathrm{~mm}$ diameter tube, and 3,6 $\mathrm{mm}$ thick wall, made by the 111 method

\section{Spawanie TIG}

Główną zaletą metody jest możliwość wykonywania precyzyjnych spoin. Ze względu na ciężkie warunki miejsca pracy, którym z reguły jest wykop też są stosowane małe przenośne inwertorowe źródła prądu. Dla grubości ścianki mniejszej niż $3 \mathrm{~mm}$ można spawać bez materiału dodatkowego jedynie gdy odstęp równy jest zero, powyżej $5 \mathrm{~mm}$ grubości zaleca się wykonywanie przetopu metodą TIG, a wypełnienie i lico elektrodą otuloną co skraca czas wykonywania złącza.

Zalecenia przy stosowaniu spawania elektrycznego elektrodą nietopliwą w osłonie gazów obojętnego:

- Pozycja spawania: wszystkie

- Metoda spawania: w prawo

- Zakres grubości ścianki: 2-5 mm

- Zakres średnic: DN20-DN200

- Elektroda: wolframowa WT20 (czerwona) o średnicy 2,4 mm

- Rodzaj prądu: DC-

- Przepływ/rodzaj gazu: 9l/min, czysty argon

- Średnica drutu: $2.4 \mathrm{~mm}$

- Ilość warstw: $2 / 3$

- Przetop: 100-120A

- Wypełnienie/lico: 120-130A

Rysunek 5 przedstawia złącze wykonane metodą 141 na rurze o średnicy $76,3 \mathrm{~mm}$ i grubości ścianki 2,9 mm. 

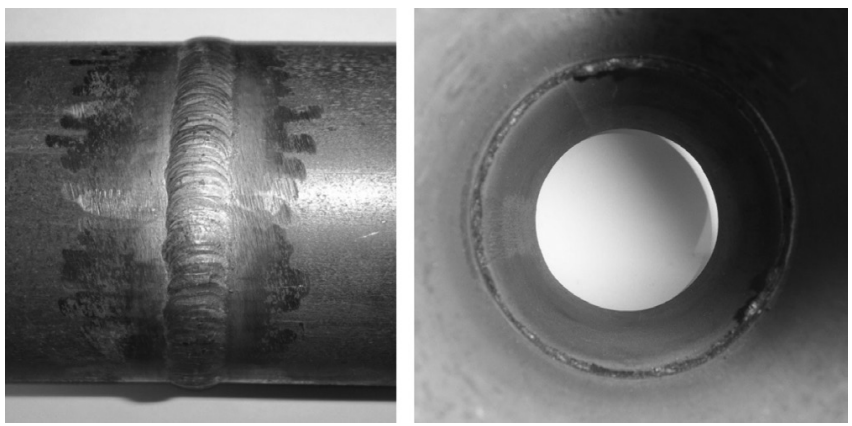

Rys. 5. Złącze wykonane metodą 141 na rurze o średnicy $76,3 \mathrm{~mm}$ i grubości ścianki $2.9 \mathrm{~mm}$

Fig. 5. A joint made by the 141 method on the tube of $76,3 \mathrm{~mm}$ diameter, and 2,9 $\mathrm{mm}$ thick wall

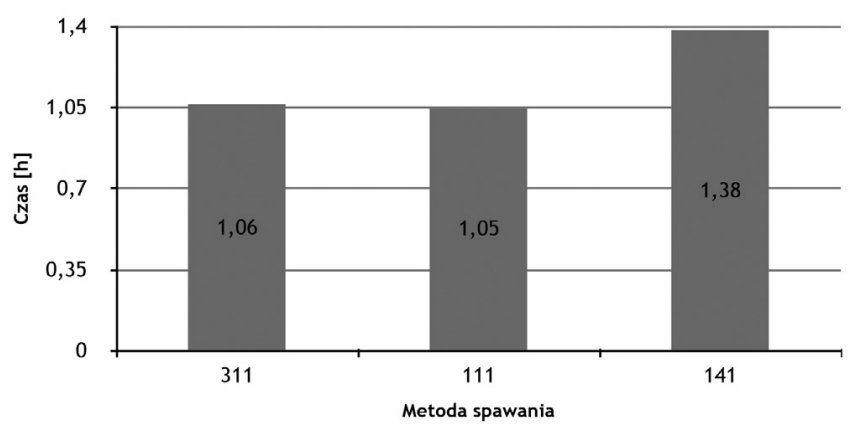

Rys. 7. Czas wykonywania złącza

Fig. 7. Time of making a joint

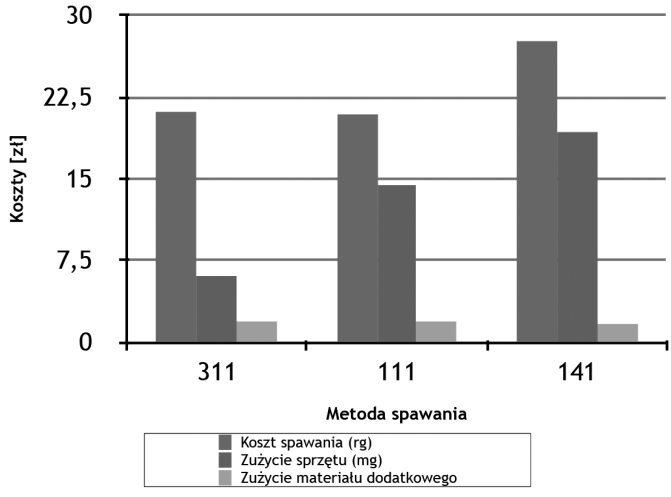

Rys. 6. Porównanie kosztów dla danej metody spawania Fig. 6. Comparison of the costs for a particular method of welding

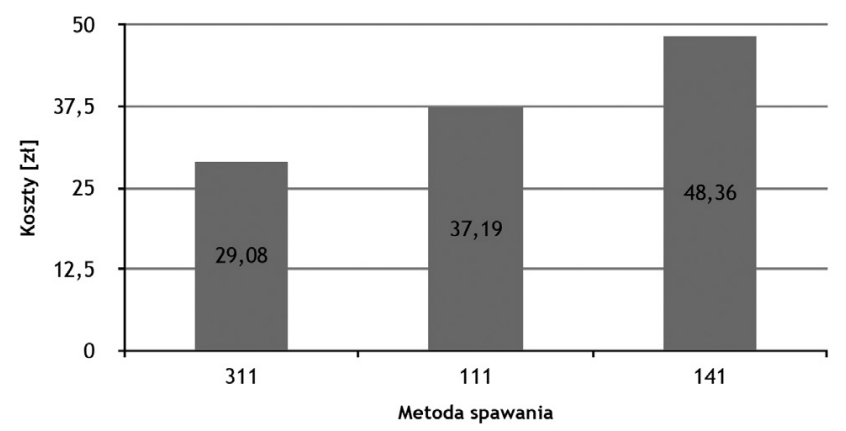

Rys. 8. Suma kosztów wykonania złącza

Fig. 8. Total costs of making a joint

\section{Wnioski}

Na rysunkach 6 $\div 8$ przedstawiono porównanie trzech metod spawania przy wykonaniu złącza spawanego na rurze preizolowanej o średnicy zewnętrznej 76,3 mm i grubości ścianki 2,9 mm. Jak można zauważyć na rysunku 6 dla każdej metody koszt materiału dodatkowego jest prawie na jednakowym poziomie i wynosi od 1,56 do $1,88 \mathrm{zł} / \mathrm{m}$. Poważny skok kosztów związanych ze zużyciem sprzętu występuje pomiędzy spawaniem gazowym a elektrycznym.

Rysunek 7 przedstawia czas wykonywania takiego złącza. Na czas złącza składa się przeniesienia i rozłożenie stanowiska, przygotowanie i wykonanie złącza spawanego.

Rysunek 8 przestawia sumowanie kosztów robocizny, sprzętu i materiału jakie musi ponieś wykonawca. Przyjęto 20 zł za roboczą godzinę spawacza oraz 10 zł za maszyno godzinę takiego sprzętu jak spawarka i agregat prądotwórczy.

W obecnym czasie najbardziej popularną metodą spawania rurociągów preizolowanych jest spawanie elektryczne elektrodą nietopliwą w osłonie gazu obojętnego, chociaż z porównania wynika że jest to najdroższa metoda, lecz cechuje się wysoką jakością spoin oraz nieiwlką liczbą niezgodności spawalniczych. Ma to duży wpływ na redukcje kosztów związanych z ewentualnymi poprawkami. Jedynymi wadami tej metody są: ograniczony zakres spawanych średnic i grubości ścianek rur oraz czas wykonywania złącza. Rury preizolowane o średnicy nominalnej większej niż DN200 zaleca się stosowanie mieszanych metod spawanie 141/111 w celu skrócenia czasu, gdzie przetop wykonuję się metodą 141, a wypełnienie i lico spoiny metodą 111. Należy się wówczas liczyć z możliwością powstawania niezgodności spawalniczy takich jak: przyklejenia, zażużlenie oraz odpryski. Takie sama sytuacja występuje przy spawaniu samą elektrodą otuloną. Spawanie acetylenowo-tlenowe charakteryzujące się bardzo niskimi kosztami, zostało kompletnie wyparte przy montażu rur preizolowanych przez metodę 141 z powodu bardzo ograniczonego zakresu zastosowania (zakres średnic jedynie do DN65). Metoda ta jest jednak wykorzystywana z powodzeniem w sytuacjach awaryjnych gdzie wykorzystywane są jej zalety, szczególnie chodzi tu o możliwość przyspawania się do bardzo skorodowanych odcinków rur.

\section{Literatura}

[1] SPEC - „Wytyczne wykonania, montażu, odbioru i eksploatacji rurociągów preizolowanych w płaszczu osłonowym hdpe (układanych bezpośrednio w gruncie)"
[2] Lubelskie Przedsiębiorstwo Energetyki Cieplnej - „Wytyczne wykonania spawania rur przewodowych sieci ciepłowniczych z rur i elementów stalowych" 